BREVE HISTÓRICO SOBRE A ARTE DE CALCETARIA EM PORTUGAL E NO BRASIL: O CASO DO MOSAICO PORTUGUÊS

Eduardo Yazigi 



\section{EDUARDO YAZIGI}

Eduardo Yazigi - mestrado e doutorado em urbanismo pela Universidade de Paris, professor live-docente do Departamento de Geografia da USP, onde leciona Política de Espaços Públicos e Geografia do Turismo, autor de cerca de +() publicaçóes has áreas de planejamento. Luristico e ambiental. Dirigiu projetos de interesse nacional como: Politica Urbana do Estado de Sào Paulo, Criação do Parque Estadual de litha Bela. Foi o úmico estrangeiro que se tornou presidente do ECOVISION - "Françar. Bienal Européia do Cinema Ambiental". Estáteminando a tese de live-docéncial sobre "O mundo das calçadas na cidade de Sáo Paulo." 


\section{RESUMO}

Este é um resumo da pavimentação urbana, especialmente, do chamado mosaico português. $\mathrm{O}$ mosaico tradicional tem origem no mundo oriental. Enquanto este é rico em detalhes, o português transforma o detalhe em motivo principal.

Nascido em Portugal no século 19, o mosaico português foi exportado ao Brasil no começo do século 20, quando muitos de seus artistas foram às colônias e ex-colônias.

Por este tempo, artista e executor eram a mesma pessoa, isto é, um trabalhador humilde sem reconhecimento social. Mas desde Burle Marx e seus riscos nas calçadas de Copacabana, na avenida beira-mar dos anos 60, a tendência é o arquiteto assumir este papel.

Atualmente o mosaico português é comumente usado nas calçadas, mas via de regra no mau sentido. Ele pode contribuir tanto à poluição visual (cada um faz o que quiser) como para resgatar a unidade dos quarteirões (quando o mosaico português é concebido num tratamento único).

\section{ABSTRACT}

This is an outline history of urban pavement, specially the so called portuguese mosaic. The traditional mosaic has its origin on the ancient oriental world. While it is rich in details, the portuguese one transforms details in the main motif.

Arising from Portugal from the XIXth century, the portuguese mosaic was exported to Brazil during the begining of the XXth, when many of its artists went to the their colonies and old colonies.

By that time, artist and executor were always the same person, that is an humble worker without social recognition. But since Burle Marx draw Rios's sidewalks on the frontwaters in the 60 th, tendence is to value the architect role.

Actually portuguese mosaic is commonly used on brazilians sidewalks, but very often on the bad way. It can both contribute to the town's visual pollution (when each one makes what he wants) and rescue the blocks unity (when portuguese mosaic is studied as a whole treatment). 


\section{INTRODUÇÃO}

Visōes de São Paulo, in: BRESCIANI, Stella. Imagens da cidade séculos XIX e XX. São Paulo: ANPUH/São Paulo - Marco Zero/ Fapesp, 1994.
Vários autores têm lamentado a destruição de cidades no Brasil. Raquel Glezer ${ }^{1}$ não vê reconstituição física possível em casos semelhantes a São Paulo, daí termos de nos consolar com outros tipos de resgate. Este resumo tenta apenas situar a questão da arte da calcetaria, mais especialmente a do mosaico português, cuja bibliografia é bastante rara em Portugal e mais ainda entre nós. Desde que o automóvel entrou em cena, as cidades se adaptaram cada vez mais ao sistema rodoviário, diminuindo a importância do pedestre. A partir dos anos 60/70, tardiamente tocadas pela falta de lugar de circulação e trocas sociais para o pedestre, as administrações começaram a introduzir alguns espaços urbanos renovados, como o nome de "ruas de pedestres" ou calçadões. Com esta preocupação instauraram-se também pavimentaçōes artísticas nos pisos destes lugares. Desde então surgiram ruas, praças, largos, esplanadas ou orlas praianas onde o paralelepípedo já não era aposto em disposições simétricas primárias. Não só os tradicionais paralelepípedos, como também granito e outras pedras; materiais cerâmicos; seixos; pré-fabricados nos mais variados formatos, entre os quais os chamados bloquetes. Dito de outra forma, ao dispor os materiais do piso de forma artística, pode-se então falar de arte da calcetaria. Sob esta forma, criaram-se inúmeras disposições com valorização do movimento, mas ainda, sem muito uso policromático. Ademais, como cobriam um todo para pedestres, não havia mais necessidade de "passeio" diferenciado e em saliência. Daí, um continum entre o piso público e os muros lindeiros, com o mesmo desenho e textura. Centenas de cidades da Europa aderiram a esta moda, sendo notáveis algumas realizações na Alemanha, Dinamarca, Itália, França, lugoslávia, Suécia, Suíça, Grécia e Espanha, entre outros. Algumas publicações como a de 
Boeminghaus $^{2}$ apresentam belas reproduçōes deste tipo de acabamento urbano. É de se considerar que nesses casos europeus, esse tipo de arte assume uma plenitude difícil de ser encontrada entre nós, visto o uso muito intensivo que temos no espaço público, seja enquanto apropriação privada, seja como concessões a permissionários ou saturamento com equipamentos das mais diversas ordens. A lista de ocupaçōes da calçada é extremamente grande e intensiva. Enquanto alguns locais são totalmente desprovidos de ocupações humanas e equipamentos, outros sofrem abusos de uso, onde se somam comércio de ambulantes; lixeiras; abrigos; hidrantes; saliências para impedir circulação e estacionamento de autos; bancas de jornal; prestações de serviços; canteiros de flores; vasos; materiais depositados por particulares; postes; muretas; praticáveis de cimento; guaritas... Por mais esmero que se tenha em relação à calcetaria, corremos o risco permanente de anular um belo projeto, já que só se torna visível em raros momentos. Nas análises que fizemos de muitos espaços públicos europeus, depreende-se a condição clean, onde até a iluminação é sabiamente disposta.

É fácil de se entender que tais aspirações são difíceis de serem conseguidas nas grandes concentrações urbanas do Brasil, dadas as condições, não só do subdesenvolvimento e de desemprego, como também do tradicional desafeto pelo espaço público que Roberto Da Matta tão bem assinalou. Igualmente, não se pode deixar de assinalar, a participação de máfias poderosíssimas, inclusive dentro da administração municipal, que manipulam a exploração comercial do espaço público em proveito próprio: basta dizer que o ponto de uma banca de jornal na avenida Paulista é estimado em U\$10.000 o metro quadrado. Mas seja como for, este tratamento do piso que pode estar presente sob qualquer uso, pode ser qualificado de "arte da pavimentação urbana" ou mais simplesmente arte
2 BOEMINGHAUS, Dieter. Pavimentos y límites urbanos. Caminos, calles, plazas, zonas públicas, peatonales y de tráfico rodado. Barcelona: G. Gili, 1984. 
Encyclopaedia Universalis. Paris: Encyclopaedia Universalis Editeur, 1989 , p. 809. da calcetaria, já que há uma preocupação estética. Esta seria a categoria mais geral; o chamado mosaico português, que será aqui destacado, constitui uma das ramificações da calcetaria, interessante, justamente, porque possui um caráter luso-brasileiro muito acentuado. Com estas preocupações, após situarmos o mosaico português historicamente, levantaremos as principais questões de seu papel no resgate da unidade paisagística.

\section{DO MOSAICO À CALCETARIA DO MOSAICO PORTUGUÊS}

É muito estreito e visível o parentesco da calcetaria com o mosaico, a ponto da primeira ser conhecida também por "mosaico português", já que traz a marca lusa que a repassou para outros lugares. A bibliografia sobre mosaicos é bastante vasta; tomaremos aqui apenas algumas referências que nos permitem entender a calcetaria. Grosso modo, o mosaico é uma forma de decoração de origem oriental, que se baseia na composição de pequenos cubos de pedra, mármore, cerâmica, vidro ou esmalte de diversas cores ou monocromáticos, aglutinados numa superfície plana, tendo como elemento de ligação cimentos, gesso ou argamassa. Foi empregado para enriquecer variados elementos, desde a joalheria e mobiliário até a arquitetura, onde pode ser encontrado em pisos e paredes. Seus motivos pictóricos não conheciam limites. Seus usos achavam-se divididos em duas grandes categorias: a) os de mármore, cerâmica ou pedras coloridas, empregados em pavimentos e b) os de esmalte, para usos mais nobres, como interiores de locais ricos, de técnica bastante complexa. $\mathrm{O}$ mosaico de pavimento, que é o que mais nos interessa, possui uma história que pode ser dividida em três grandes períodos. ${ }^{3}$ O primeiro deles é denominado "mosaico de seixos" (século 8 ao século 3 a.C.); o segundo, com técnica que já permite 
cenas pictóricas (século 3 ao 1 a.C.); o terceiro, que se estende desde então até o século 7 d.C. e que é aquele do pavimento greco-romano, quando houve uma verdadeira industrialização desta arte.

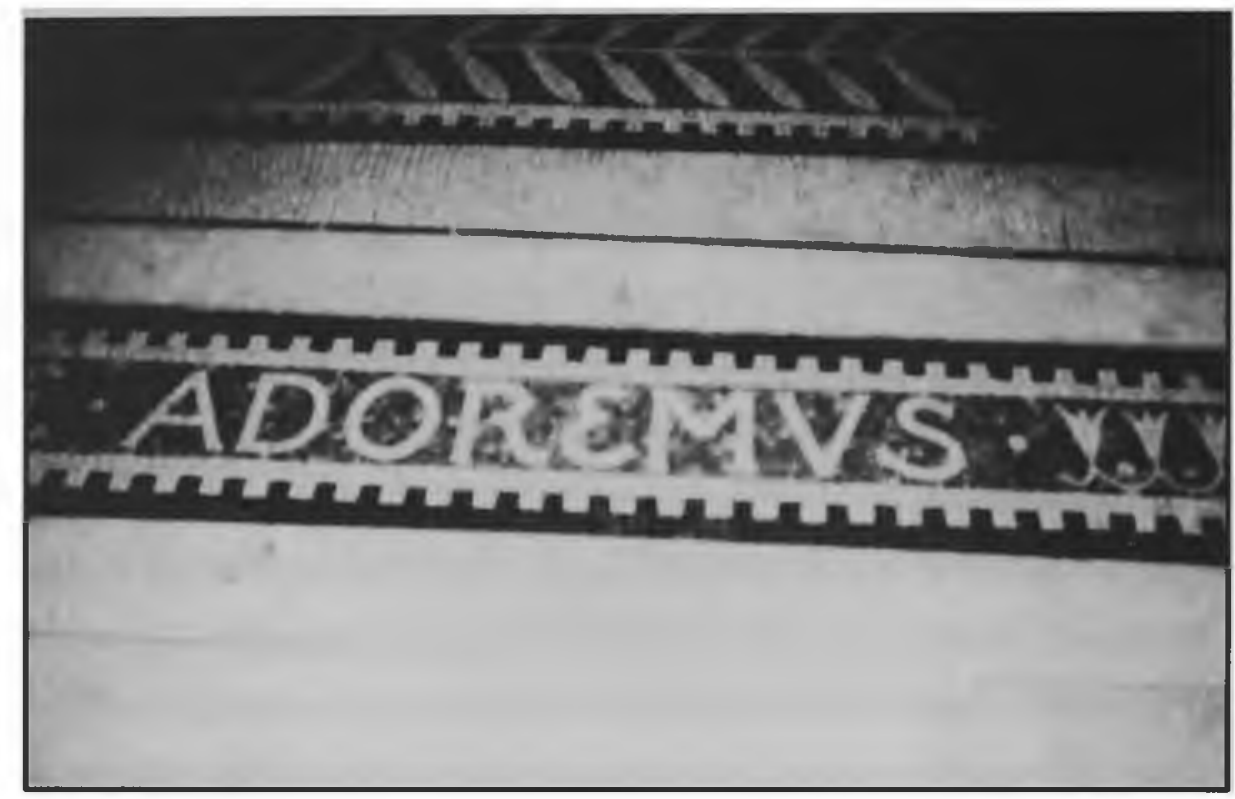

O calçamento de vias públicas é bastante antigo, conhecendo-se vários sítios arqueológicos nos mundos greco-romano e oriental. Mas neste caso queremos distinguir um simples calçamento de pavimentação artística. Numa carta régia de 20 de agosto de 1498, D. Manuel já determinava que continuassem as obras das calçadas: à cidade cabia pagar a mãode-obra; aos proprietários das casas e proprietários de veículos competiam as achegas (materiais e transportes); a nobreza e o clero, não tendo sido poupados de contribuição, procuraram fazer oposiçāo. Pela carta régia de 8 de maio de 1500, D. Manuel despacha o calcetamento da rua Nova Grande dos Mercadores, com pedra do Porto, "porque a outra dana-se na maneira que vedes"... O mosaico português ainda não tinha feito sua aparição.

Em Portugal, encontram-se vários mosaicos romanos notáveis, tais como os de Conímbriga, Pisões, Faro, Lagos, Lisboa,
Mosaico da Capela do Santíssimo, do Mosteiro de São Bento de Sāo Paulo Foto do autor. 
FRANÇA, José Augusto. $A$ arte em Portugal no século XIX. Lisboa: Bertrand, 1966.
Portimão, Torres Novas, Porto... No Alentejo, já se tem calcetamento desde os árabes. A variante lusa do mosaico é conhecida por "embrechado", podendo ainda hoje ser notado em paredes de velhas quintas. Entretanto, rememorando a história da arqueologia, verificamos que Pompéia é descoberta no século 18 e Conímbriga no século 19. Ora, temos referência de que a primeira calçada de mosaico português, com desenhos em zig-zag, foi mandada fazer pelo tenente-general Eusébio Cândido Cordeiro Pinheiro Furtado, governador de Armas do Castelo de São Jorge na parada do Batalhão de Caçadores 5, em $1842^{4}$ É possível, pois, que este militar tenha se inspirado nos vestígios arquelógicos de Portugal, para levar a cabo seu projeto, realizado por carcerários, então denominados guilhetas. É que havia elo entre os geólogos do exército e os arqueólogos. Não deixa de ser curioso que os dicionários de língua portuguesa assinalam o termo "calceta" para designar presidiários condenados a trabalhos forçados. Talvez a origem se prenda ao Batalhão de Caçadores.

No entanto, do mosaico romano ao português há diferenciações que cumprem ser notadas, já que definem as características deste último e lhe conferem autonomia. Enquanto que o mosaico tradicional é uma arte decorativa freqüentemente fundamentada no ornato, no rigor dos detalhes e na cor, o mosaico português é antes utilitário, bicolor, transformando o pormenor em motivo principal. Ele foi criado para espaços livres, para ser pisado e resistir às intempéries. $\mathrm{O}$ mosaico romano de pavimento é delicado, feminino, próprio dos interiores: não resistiria muito ao uso intensivo. No Brasil ainda podem ser encontrados vários pisos de mosaico, mas, como é natural, preponderantemente em interiores. A igreja do Mosteiro de São Bento em São Paulo, como vários templos (capela do Convento do Carmo, em São Paulo...) e algumas mansões remanescentes da virada do século ou do surto 
industrial dos anos 30, exibem ainda belíssimos exemplares. Modernamente há uma redescoberta do mosaico, feito com cacos de mármore, pastilhas ou vidrotil.

Não pode deixar de ser lembrado que o Brasil descobriu e utiliza amplamente o ladrilho hidráulico para revestimento de calçadas. É notável como a partir de três unidades: um ladrilho branco, outro preto e um terceiro meio a

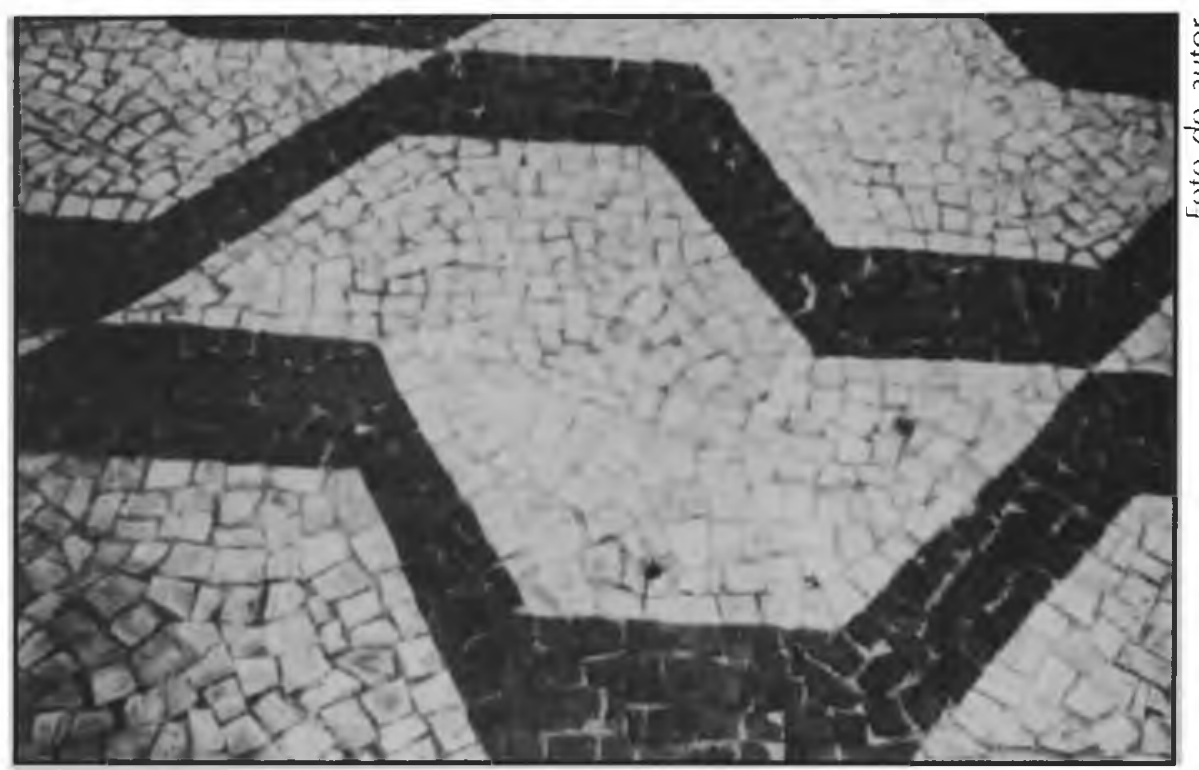

Calçada padrāo de Sāo Paulo meio pela diagonal, obtém-se uma quantidade imensa de desenhos, tais como o célebre mapa estilizado do estado de São Paulo, (ou o "pijama xadrez" no jargão dos calceteiros) que faz parte da identidade da urbe, mas é raramente obedecido nos remendos. Alguns lugares trazem a marca precisa de sua etnia - o yang.e ying dos pisos do bairro da Liberdade, São Paulo, concentração de colônias asiáticas. A rua Augusta vai configurando desenhos espontaneamente, guidados pelo interesse de seus comerciantes. Outros pontos do centro, como o Arouche, chegaram a formar uma associação para estes fins. É a tomada de consciência da importância do piso.

\section{A DIFUSÃO DO MOSAICO PORTUGUÊS}

Dado o sucesso prático e estético obtido pelo tenente-general Pinheiro Furtado, a Câmara de Lisboa fez logo aprovar a concessão de recursos para a pavimentação de toda a placa 


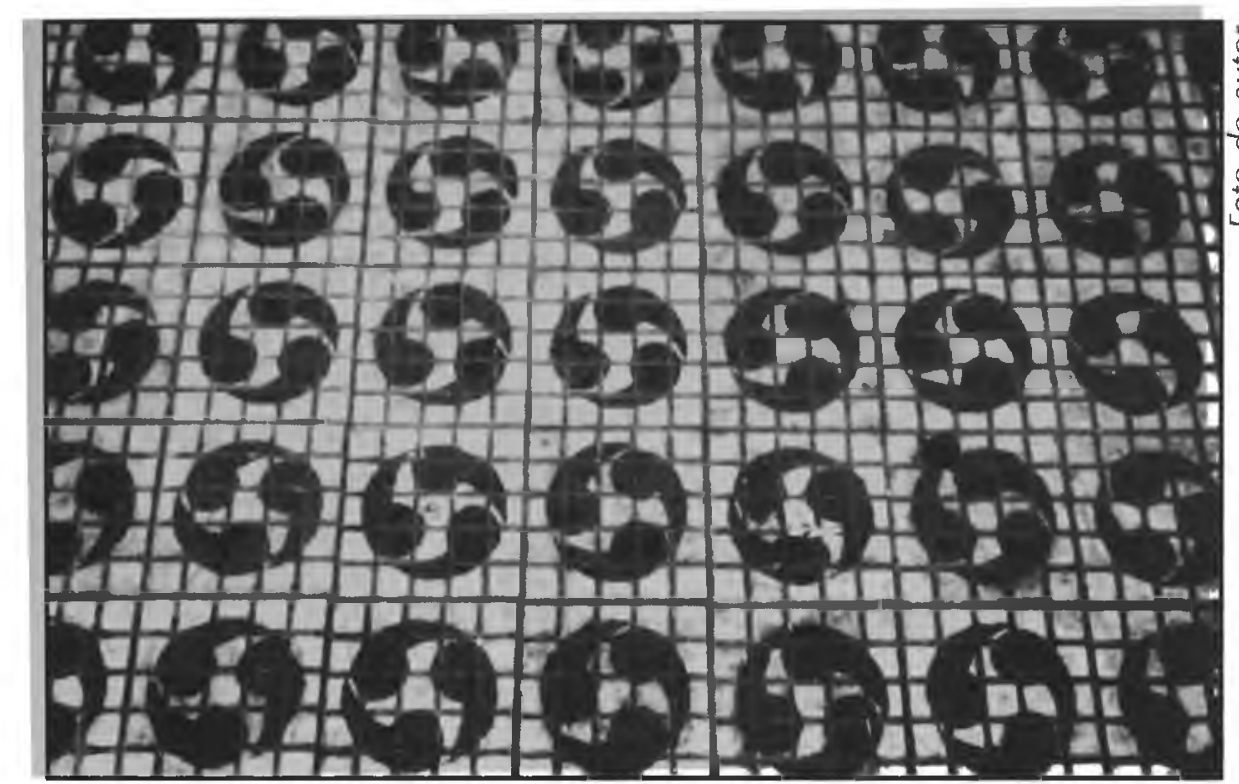

Calçada do bairro da Liberdade, SP, inspirada no símbolo Yang-Ying

central da praça do Rossio, cobrindo uma área de $8.712 \mathrm{~m}^{2}$ entre 1848 e 1849. Aliás, desde o século 19, em muitos países, inclusive no Brasil com Osvaldo Cruz, passa-se a acreditar muito em obras de saneamento que incluem, entre outras coisas, uma rede de esgotos e pavimentações. Assim, pela obra do tenentegeneral e outras obras que the seguiram, o mosaico português firma-se como caracteristicamente lisboeta. Efetivamente, já em 1863 é calcetado o largo do Carmo; em 1867 o largo de Camões; em 1870 o jardim Patriarcal; em 1876 a praça dos Municípios e o largo São Julião; em 1877, a praça dos Remolares - atual Duque da Terceira. Trabalharam nestas obras assinaladas: Ângelo Rodrigues Chaves; Francisco Manuel Anil; João Rodrigues; Joaquim Branco; Manuel Pereira (o "Pereirinha"); José Amâncio; Manuel Antonio Passos e Manuel Joaquim. Os trabalhos em mosaico português prosseguem, incluindo o largo do Chiado (1886); rua Garret (1888); avenida da Liberdade (duas placas, 1889); rua Antonio Maria Cardoso (1893) e jardim de São Pedro de Alcântra (1894), com a participação dos calceteiros José Pacheco; João Francisco; Manuel Gonçalves (o "Manuel Padeiro"); Manuel Joaquim (o "Quizumba"); Matias José Nicolau; Carlos Lopes; Antonio Jorge; Joaquim Abrantes e Paulo Cândido. Os mesmos participam ainda do calcetamento da avenida da Liberdade (1900-1908); praça do Comércio (1907) e praça Marquês de Pombal (duas placas, em 1910). A receptividade vinha sendo tal que a difusão se tornou inevitá- 
vel: é assim que a arte portuguesa de calcetaria participa da Exposição de Paris de 1900, com a presença de João Cândido; Antonio Jorge; José Francisco; Francisco o Machado e José. Neste tempo, Manaus estava ainda no ciclo de ouro da borracha, que desde os fins do século 19 vinha promovendo intensos trabalhos de modernização: construção do Teatro de Manaus, obras de saneamento; arborização, decoração da cidade... É assim que lá chegam, em 1905, José da Costa; Bento da Cruz e Francisco Antunes Cabral. Contemporaneamente, para a pavimentação da avenida Rio Branco, no Rio de Janeiro (exavenida Central), chegam 22 calceteiros, entre os quais, Jaime Pinto Freitas Guimarães; Manuel Lopes; Antonio José Rodrigues; Manuel Rodrigues; Antonio Carvalho; Manuel dos Santos; Eduardo Augusto; José Francisco Cerdeira e Antonio da Costa ${ }^{5}$. O calcetamento se fez ainda presente com a ida de artistas portugueses à cidade do Cabo em 1909; a Nápoles em 1913 e a Sevilha em 1929 e 1969. Mas foi com a presença em Manaus e Rio de Janeiro, que inclusive receberam carregamentos da pedra necessária, que se inaugura, entre nós, a tradição da arte da calcetaria. Assim, no primeiro quartel deste século, o calçamento de algumas cidades brasileiras com mosaico português já chamava a atenção de observadores estrangeiros. Falando do Rio de Janeiro, em 1930, um deles tece um curioso comentário ${ }^{6}$ sobre a avenida Rio Branco, cujos desenhos "laid in zigzags and in other dizzy patterns" nas calçadas lhe causavam tontura...

"One of the unique features of the street is it's sidewalk, made up of stones laid in wavy patterns"..."To walk this street on a hot sunshine day calls for steady nerves" (p. 739).

Em São Paulo, há várias calçadas de mosaico português. Todavia, é digno de nota que não só o espaço público comportava esta modalidade de revestimento. Ele é próprio também de
5 Grande Enciclopédia Portuguesa e Brasileira. Lisboa/Rio: Editorial Enciclopédia Ltda., 1960, vol. XX, p. $538 \mathrm{sqq}$. SIMPICH, Frederick. Gigantic Brazil and its Glittering Capital. In: The National Ceographic Magazine, dec. 1930. 
espaços internos, públicos e semipúblicos, palácio dos Campos Elíseos e algumas mansões que ainda restam naquele bairro, assim como Higienópolis e Ipiranga. Com a industrialização do Estado Novo, vários industriais foram residir perto de suas fábricas. É o caso da "Casa dos Jafet", situada à rua Bom Pastor, n. 798, com jardins cortados por belos espécimens seguramente muito influenciados pelo vizinho parque da Independência no contexto do Museu do Ipiranga. Mas outros, lamentavelmente, permanecem em péssimo estado como regra geral, tal como a parte anterior da praça da República, nas costas do Caetano de Campos; no singular desenho do chão da praça do Patriarca, junto à Galeria Prestes Maia; na própria avenida Paulista...
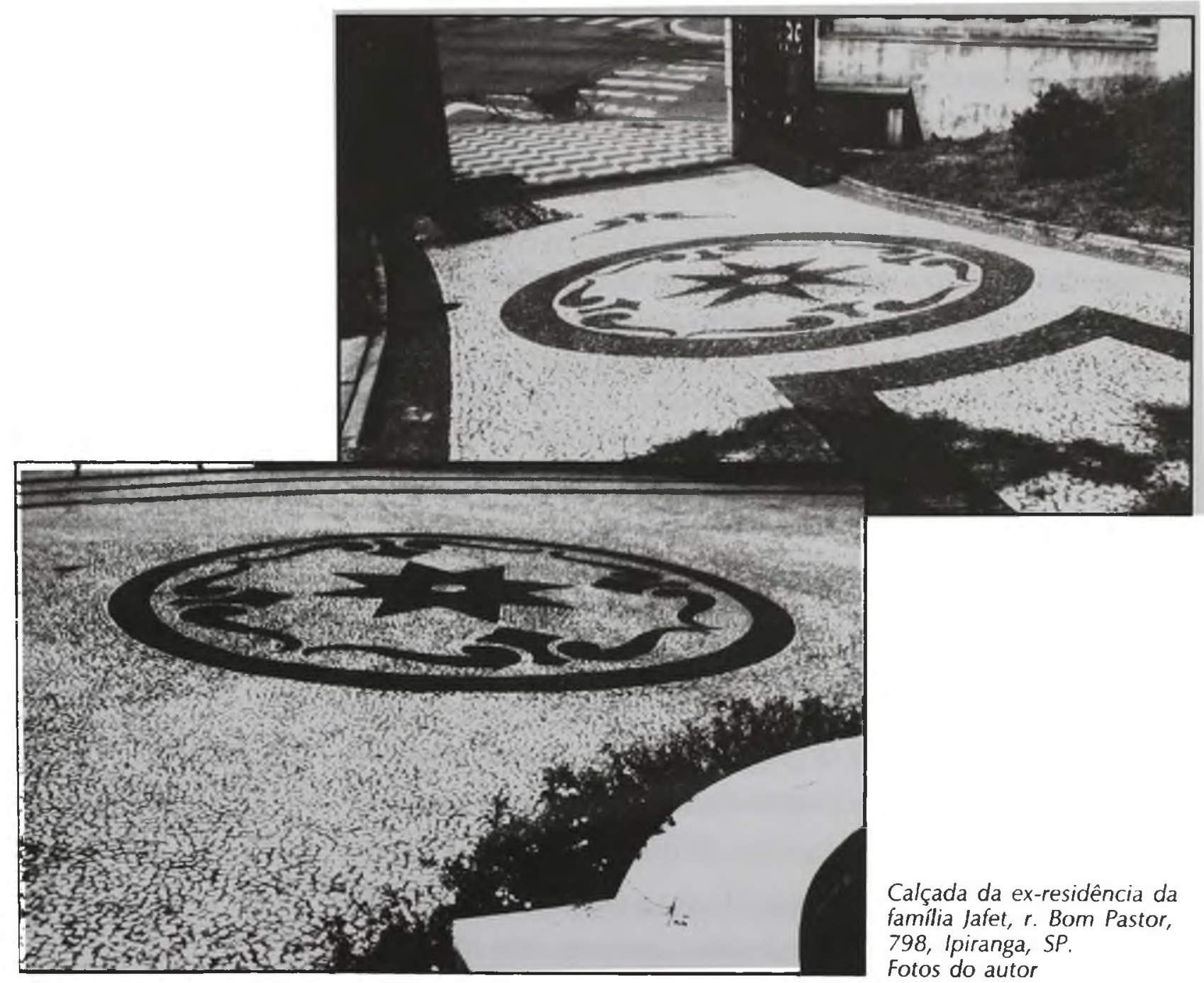

Calçada da ex-residência da família Jafet, r. Bom Pastor, 798, lpiranga, SP.

Fotos do autor 


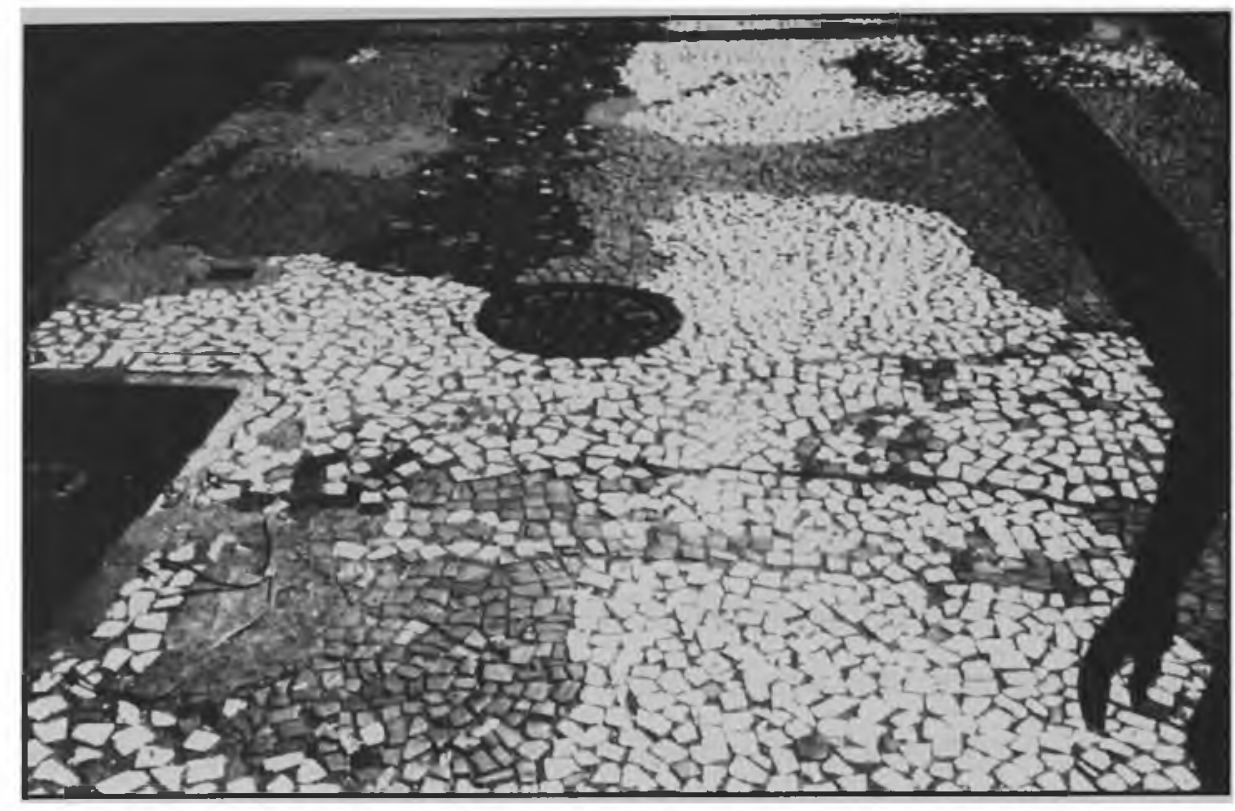

Durante a década de 60, com o aterro do Flamengo, Burle Marx reconhece a beleza plástica da pavimentação com mosaico português, projetando as calçadas do Rio de Janeiro que the valeram celebridade internacional. Sobre isto comenta Flávio Motta:

"O revestimento de Burle Marx, em mosaico com pedras brancas, pretas e avermelhadas é uma velha técnica adequada à dilatação. O desenho assumiu outro sentido, acrescentando alguma coisa à noção de cidade feita pelo homem, dentro de um determinado processo histórico. Demonstra-se assim que a arte, quando amplia a área de participação social, permite o pleno reconhecimento dos projetos fundamentais por vezes apenas insinuados nas primitivas pinturas e desenhos. Os conhecimentos de tela, em ininterrupta atividade pictórica, foram por Burle Marx transferidos para uma longa calçada à beira da praia. ${ }^{.7}$

A este propósito, conviria uma certa observação que talvez explique porque, apesar do sucesso da calcetaria portuguesa em muitos países, seus grandes artistas permanecem obscuros. Possivelmente isto se deve ao fato de que, como no início pelo menos, a figura do calceteiro-artista era a mesma do calceteiroobreiro, isto é, de origem humilde, um peão de obra... Foi
Calçada remendada. São Paulo Foto do autor

7

MOTTA, Flávio. Roberto Burle Marx e a nova visão da paisagem. Sāo Paulo: Nobel, 1983. 
CABRERA, Ana, NUNES, Marília. Olhar o chão. Lisboa: Indústria Lever Portuguesa Ltda. Imprensa Nacional Casa da Moeda, 1990, p. LII a LV. somente com a apropriação da técnica por arquitetos e paisagistas, que o mosaico português passa a ter o merecido destaque na bibliografia. Sem dúvida Burle Marx reinaugura uma tradição que hoje vem sendo continuada por artistas plásticos e arquitetos, enquanto autores de projetos de calcetaria, mas não executantes. Há, ainda, toda uma pesquisa a ser feita com os poucos calceteiros e seus descendentes que ainda vivem no Brasil, especialmente em São Paulo: nossa preservação da memória, quando ocorre, tem sido quase que só da elite. Não nos importamos, por exemplo, com todo mundo da cultura material do caiçara e do caboclo, que permanecem quase que somente em nível de trabalhos acadêmicos.

\section{MATERIAIS, TÉCNICA, ASSINATURA}

Dada a existência de calcário e basalto nas cercanias de Lisboa, foi destas pedras que o mosaico português se serviu. No entanto, como a composição de desenhos exige apenas o jogo entre o claro e o escuro, entende-se que fica bastante facilitada a escolha entre os materiais disponíveis em locais diferentes. Duas autoras portuguesas ${ }^{8}$, que redescobriram a importância da calcetaria, produziram uma bela publicação da qual extraímos algumas lições:

"A execução da calçada artística exige que o facetamento dos cubos obedeça a regras impostas pela complexidade do painel... A fractura da pedra é feita na concha da mão, com perícia e precisão, numa cadência ritmada. As arestas são buriladas, polifacetadas, multiplicando-se as formas com imaginação e mestria... Surgem hexágonos ou o sextavado, as conchas para áreas restritas; os cubos regulares que originam a calçada a correr; os paralelepípedos irregulares ou malhete e que constituem a primitiva calçada portuguesa...

Os calceteiros escavam o local, à pá e picareta, formando uma caixa com cerca de 8 centímetros de fundo, 
sobre a qual acamam uma base de areão e caliças. É sobre este aparelho, uniformizado pelo rodo ou tabuado, que procedem ao acentamento dos pequenos cubos de pedra, já devidamente talhados e adaptados às exigências do desenho e ao molde, previamente embutido na caixa, com a ajuda da cavilha de fixação. Usando o martelo de bico, ajustam ou aconchegam os módulos uns aos outros; de seguida espalham uma cobertura de areia e/ou caliça e regam-na, formando assim uma massa aglutinadora, que penetra nas juntas, evitando folgas entre as pedras.

Por fim, desempenam o painel. Os batedores de maço mais experientes fazem-no à vista. Pisam a calçada, nivelando-a de molde a proporcionar uma regularidade alfombrada."

No Brasil, vem se notando um uso preponderante do cimento no lugar do saibro para se fixar as pedras, da mesma forma que se faz com paralelepípedos do leito carroçável.

O mosaico português apresenta uma curiosidade no tocante à assinatura do artista que compôs a calçada:

“... quase todos os ornatos mais importantes (como por exemplo os florões da Avenida) estão assinados com uma rubrica que os entendidos conhecem logo. Essa assinatura é uma pedra. Este artista colocará no centro do seu florão uma pedra em triângulo aguçado; aquele assina com uma pedra em quadrado; outro firma com um pedaço de calcário que talhou em hexágono ou em concha. E essa forma da pedra constitui uma assinatura que os calceteiros reconhecem e mantêm. Uma caravela que se encontra no passeio da Rua da Palma, à entrada do velho Palácio Folgosa, dá um belo exemplo de assinaturas. Foram destacados para fazê-la os melhores artistas. $\mathrm{Na}$ parte superior direita as pedras são em concha, hexagonais na parte inferior média etc. Outra forma de assinatura é a do proprietário do prédio confinante, etc. O capitalista Carvalho Monteiro, proprietário de numerosos prédios, assinalava as suas propriedades mandando calcetar os passeios com estrelas. Era conhecido por toda 
Grande Enciclopédia Portuguesa, p. 542. a Lisboa por 'o Monteiro dos Milhões', alcunha que soava familiarmente aos ouvidos de todos que freqüentavam a sociedade de Lisboa. Pois as estrelas, de que os calceteiros ainda conservam os moldes, são conhecidas pela alcunha de 'As estrelas do Milhões' "9.

\section{A CALÇADA COMO ESTEIO DA UNIDADE URBANÍSTICA}

Vista a importância histórica de calcetaria, entende-se então como a mesma pode e deve ser objeto de composição da paisagem. O desvirtuamento do desenho no chão não é o único responsável pelo caos visual de muitas cidades brasileiras, nem é a única forma de se conquistar a unidade do conjunto. A calcetaria é só um dos fatores, mas que pesa muito. Ao lado dela poder-se-ia colocar leis de uso e ocupação do solo e códigos de obras, como reguladores de padrões desejáveis gabaritos, recuos, fachadas, etc. - em futuras urbanizações que aspirem unidade. Nas restaurações em que a paisagem foi desvirtuada, a calcetaria poder ter relevante papel, tanto quanto restaurações de edifícios ou ainda de padronização cromática de fachadas e arborização.

A história de nossa urbanização, incluindo a produção arquitetônica, revela que em virtude dos processos econômicos vigentes por ocasião de expansão das cidades brasileiras, e mesmo hoje, raros são os casos em que se conseguiu padrões de unidade. Em outras palavras, a paisagem urbana é extremamente fragmentada dos mais diversos pontos de vista: o mais comum é que nela coexistam produções não relacionadas entre si, frutos em especial de zoneamentos e códigos de obras de muita tolerância ou ainda a permissividade administrativa: fiação aérea em profusão, publicidade ao gosto de cada um... Como se isto não bastasse, a história das administrações mostra organogramas onde, com freqüência, órgãos 
setoriais atuam sem coordenação efetiva (que em cada cidade leva uma sigla diferente), resultando na fragmentação visual e física do chão urbano. As calçadas são um retrato destas posturas. Qualquer brasileiro sabe que neste país é muito difícil encontrar uma quadra que seja, isenta de remendos, mesmos nos bairros tidos como os de maior renda per capita... As empresas públicas e privadas que atuam na infra-estrutura urbana de São Paulo, tais como instalação de encanamento de gás (Comgás); eletricidade (Eletropaulo); de água potável e esgotos (Cetesb, DAE); de cabos telefônicos (Telesp); TV a cabo, entre outras, operam de modo muito a desejar. Na falta de planejamento mais eficaz, que tenha em conta horizontes de tempo mais amplos, impera o imediatismo, resultanto num abre-e-fecha de calçadas "que não termina nunca" Daí os remendos de milhares de quilômetros de extensão, quando não, buracos propriamente ditos. Tudo devido a uma falta de sincronia mais eficaz; de uma coordenação efetiva inexistente. Estrangeiros se espantam com este desleixo ${ }^{10}$ - não sem razão, num momento, em que pela primeira vez entre nós, se fala e reivindica o direito ao entorno. Como se sabe, os direitos vêm sendo classificados por gerações: os de primeira geração dizem respeito aos direitos políticos; os de segunda aos direitos sociais; os de terceira ao meio ambiente e entorno e, os de quarta, à engenharia genética. A exemplo de São Paulo, a maioria das cidades brasileiras demonstram este descaso pelo espaço público, sendo raríssimas as exceções.

Na ótica de uma revisão da política de espaços públicos, relacionada com a cidadania e seu direito ao entorno, somos de opinião que a calçada pode e deve funcionar como fator de estabelecimento de alguma unidade em nosso meio urbano. Quando um conjunto arquitetônico apresenta falta de unidade na expressão externa, o que é o caso crônico do Brasil, algumas
10 BUBRANNA, JeanMarc. São Paulo, in: Le P'tit Bleu. São Paulo, n. 13, p.3,nov. 93, 
11 ANDRADE, Francisco de Paula Dias.

Subsídios para o estudo da influência da legislação na ordenação e na arquitetura das cidades brasileiras. São Paulo, 1966. Tese (Doutorado) - Escola Politécnica da Universidade de São Paulo. técnicas relativamente simples podem concorrer para a conquista da unidade. Supondo-se a impossibilidade de obras de envergadura, entendíveis em nossa realidade econômica, há casos em que o tratamento cromático de fachadas pode estabelecer uma ordem em que se conheça o pertencimento mútuo. Isto ocorre sempre que uma associação privada, ou oriunda do poder municipal, tenha interesse na promoção do lugar. A arborização de calçadas, pela linearidade e regularidade pode, igualmente, desempenhar o papel de estabelecimento de unidade. Árvores do mesmo porte, de preferência da mesma espécie ou em alternância regular com outra podem reforçar o efeito unificador da paisagem, do ponto de vista do transeunte. Aliás, basta se atentar para muitas ruas arborizadas de São Paulo, onde a unidade arquitetônica não existe, para se dar conta do papel múltiplo da vegetação. $\mathrm{Na}$ mesma linha de intervenção, a organização da calçada e da própria arte da calcetaria no leito carroçável complementam esta possibilidade, desde que tenham a unidade como princípio, associada à clareza da leitura geral. É isto que permite o resgate. Ou talvez nem resgate, mas conquista, já que desde os idos coloniais que não se tem mais um mínimo de padrões arquitetônicos. Mas as coisas não são assim fáceis, quando se lembra que já em 1966, como assinalou um autor, nada menos de 600 entidades intervinham na organização espacial da rua!"1 Hoje são vários milhares. Curitiba é um exemplo magistral de como isto pode ser superado, graças a ensaios conseqüentes de planejamento urbano. Lá, não só os padrões de quarteirão são obrigatórios, como têm ocorrido pesquisas no sentido de aprimorá-lo. Por exemplo, além dos motivos regionais utilizados nos mosaicos portugueses, dá-se ainda ao luxo de programar informações no chão, onde uma linha destacada de pedras indica o trajeto turístico para o forasteiro... Numa praça, Carlos Gomes, o mosaico português com liras; nas ruas centrais, o desenho do pinhão ou da araucária... 


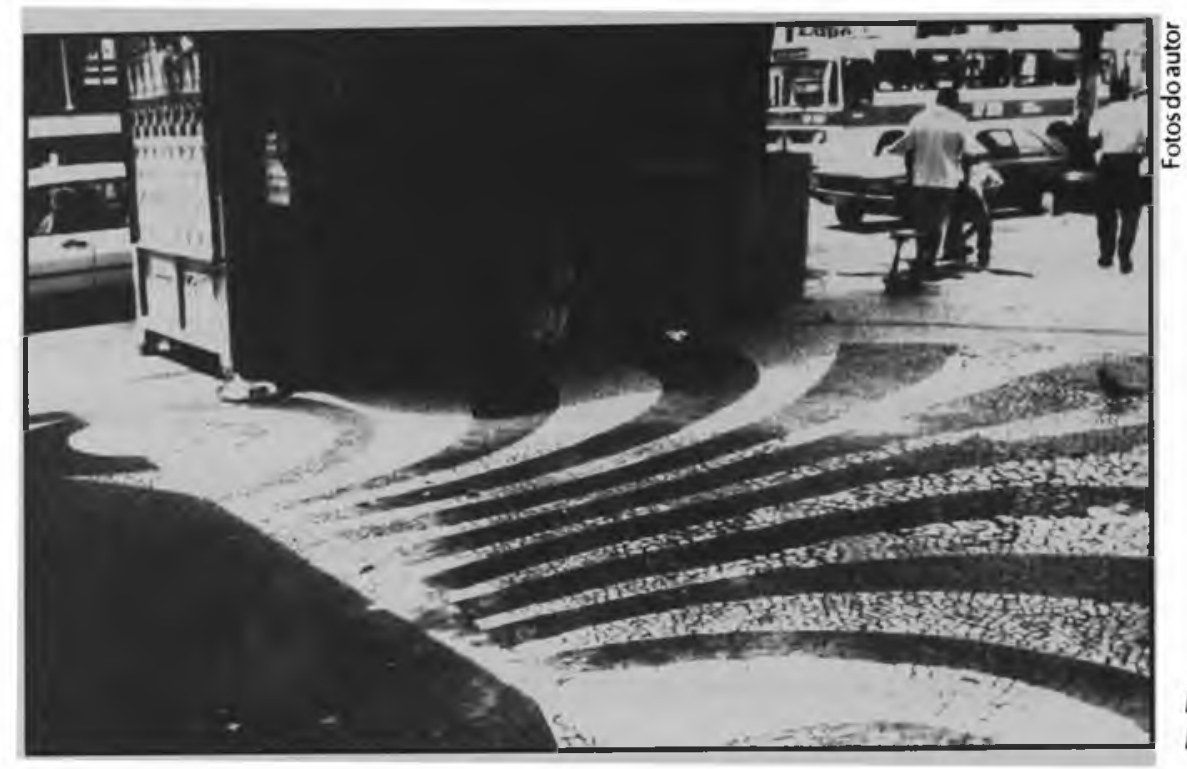

Praça do Patriarca, SP Foto de Zorzete.

Rua dos Timbiras, SP.
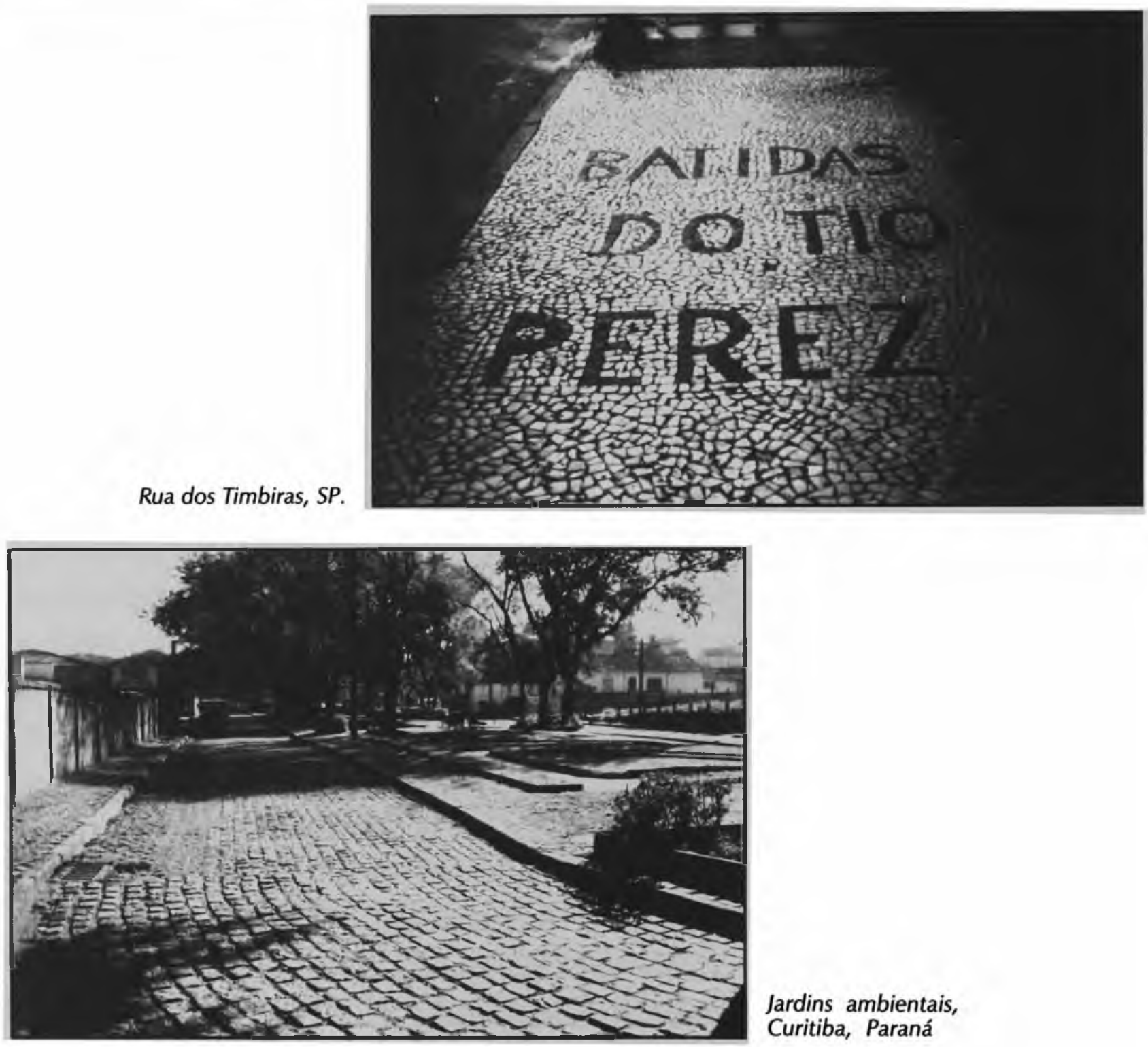

Jardins ambientais,

Curitiba, Paraná 


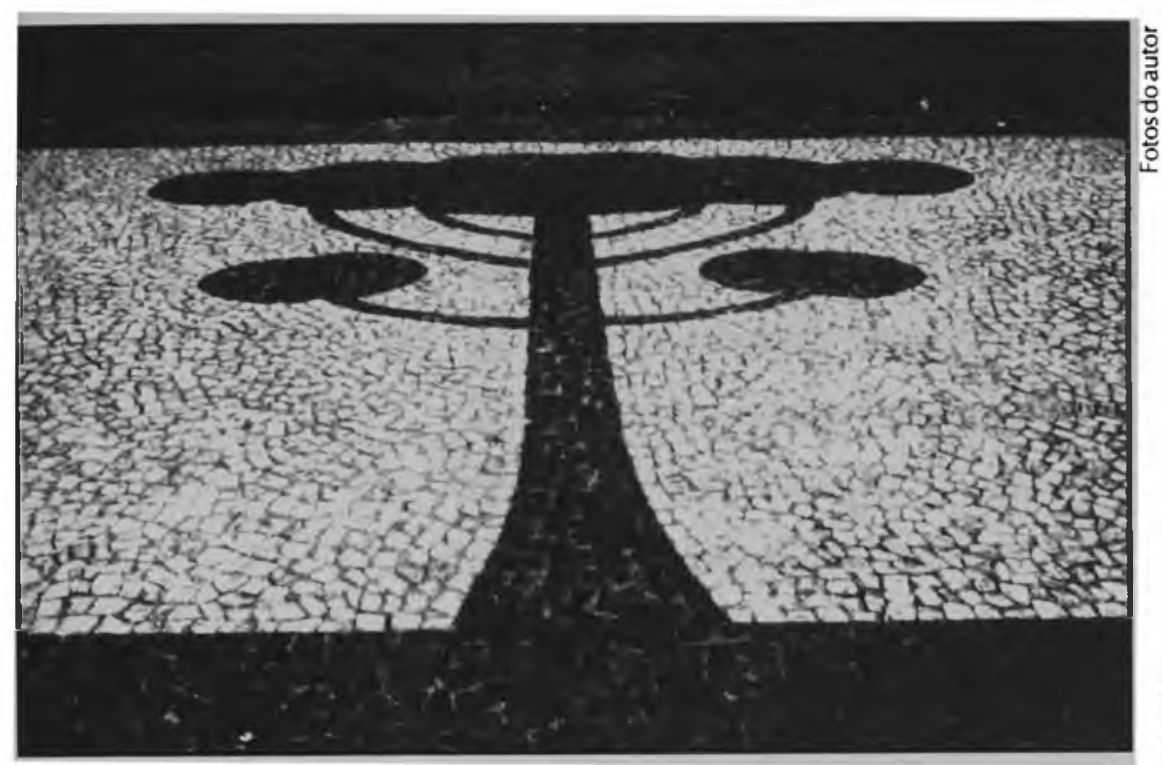

Motivos regionais: pinheirinho.

Curitiba, Paraná

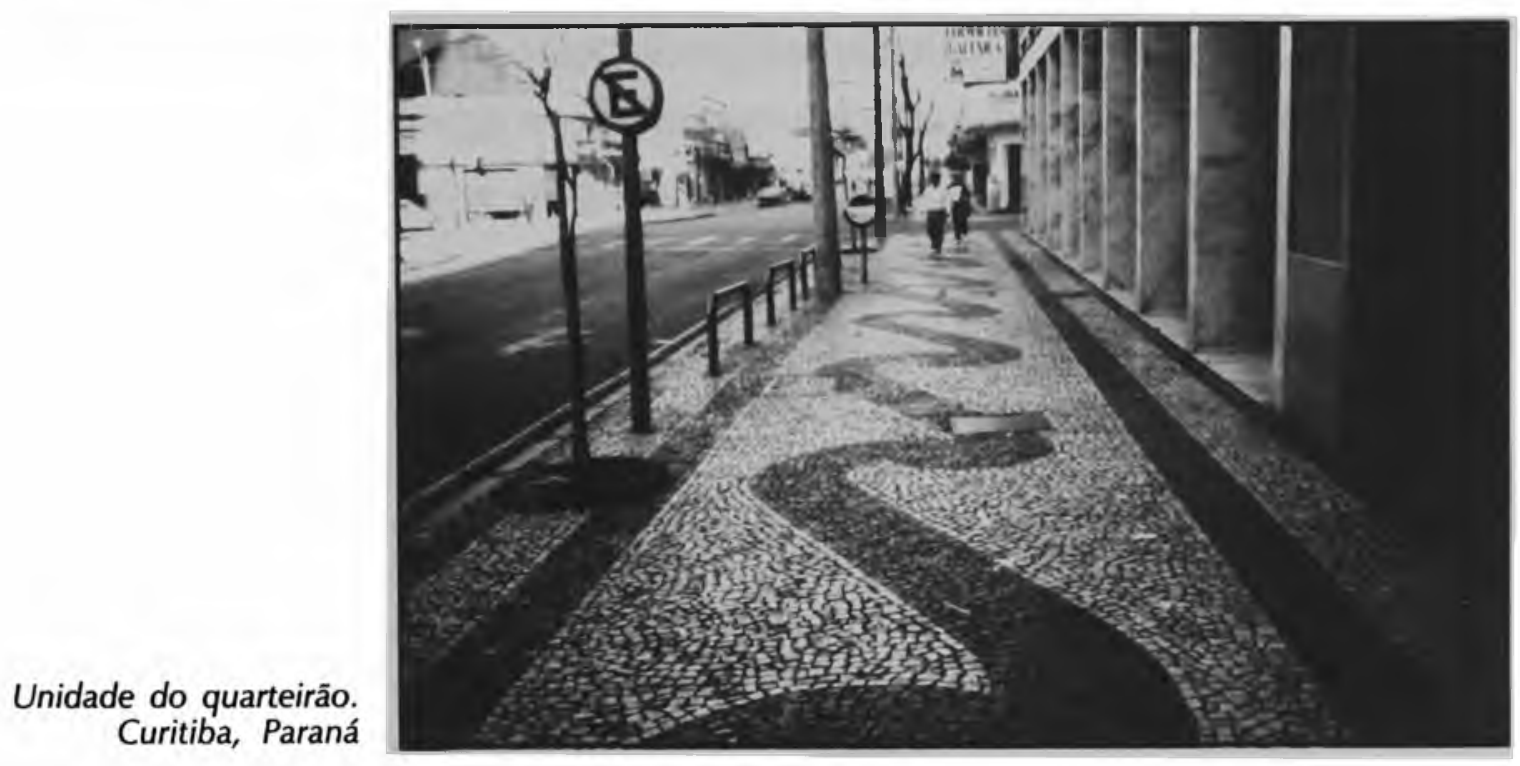

No entanto, o cuidado com modismos recomenda que não se parta para uma profusão indiscriminada. Cada caso é obviamente um caso em que todo o entorno tem de ser considerado, sendo plenamente admissível que em certas circunstâncias se deva mesmo impedir qualquer tipo de desenho. $\mathrm{O}$ mau uso deste pode levar ao efeito inverso do desejado. Paris é um dos muitos lugares onde o calçamento no cimento ou no betume se apresenta como o mais recomendável, não só para valorizar as fachadas, como para evitar a poluição visual. Um exemplo recente mostra a que grau os franceses têm dado atenção à 
questão da calcetaria. Como se sabe, a place Vendome de Paris constitui-se numa das mais aristocráticas do planeta. Quando, por motivos não muito bem justificados se substituiu seu antigo piso neutro, monocromático, por outro também liso e neutro, mas em forma de pequenos quadriláteros, originou-se, como não poderia deixar de ser, toda uma textura que alterou consideravelmente o visual da praça. Os simples sulcos da justaposição de ladrilhos e não a monocromaticidade, passaram a incomodar!!! Desde então surgiu uma crítica severa. Uma delas provém de uma professora da Faculdade de Arquitetura de Versalhes, que estudou alguns aspectos recentes do uso das calçadas de Paris, em texto publicado pela Gallimard ${ }^{12}$. Na sua opinião, praças como esta assumiram o ar de gigantescas "cozinhas" ou "banheiros", visto o tipo de piso usado em substituição, todo quadriculado...

"Nous avons totalement perdu l'expérience des antiques, renaissants, classiques, néoclassiques et autres haussmanniens dans ce domaine, pourtante si essentiel: l'harmonie des pleins et des vides, le contraste des horizontales et des verticales, la subtilité méditée des changements $d^{\prime}$ echelles"..."Alors, on débouche invariablemente sur des effets de carrelage, invariablemente sur les places prestigieuses en grandes salles de bains ou en gigantesques cuisines à ciel ouvert." (p. 290)

A péssima manutenção das calçadas de São Paulo tem sido motivo de inúmeras chamadas por parte da imprensa. Usualmente, como em outras partes, a manutenção das calçadas é atributo do proprietário do imóvel lindeiro (ou da concessionária que as danificou). Ora, obrigá-los indiscriminadamente a recompor possíveis desenhos tem de ser considerado com muita cautela, pois o mais provável é que resultem em aberrações ainda maiores: não se trata apenas de tapar buracos deste abre-e-fecha-que-não-termina-nunca.
2 MOSSER, Monique. La guerre des trottoirs. Ou les nouveaux embarras de Paris. Debat, Gallimard, n. 80, Mai-Août 1994, p. 281-192. 
São dignos de nota os trabalhos que um setor da Secretaria Municipal de Cultura desenvolveu, com a pesquisa histórica, no sentido de descobrir quais eram os padrões artísticos das calçadas, a fim de reincorporá-los em certos espaços renovados do centro de São Paulo. Um desses pesquisadores, com trabalhos implantados, é o artista plástico Francisco Zorzete, que liderou um trabalho pioneiro de restauração da arte da calcetaria em São Paulo, iniciado em 1991, durante a gestão da prefeita Luiza Erundina, no contexto da Secretaria Municipal de Cultura. Foi então questão de se restaurar o eixo SéArouche, parcialmente realizado numa busca de pesquisas fundamentadas em fontes fotográficas e iconográficas. A ele se devem as restaurações da praça Ramos de Azevedo e do parque da Independência. A pesquisa do centro da cidade revelou a preexistência de calçadas que fazem parte da construção de nossa identidade. Daí o cuidado de ser muito criterioso nas obras de restauração: o viaduto do Chá, por exemplo, deveria ter seu piso de ladrilhos com o mapa de São Paulo retirado, para nele se recolocar os ladrilhos hidráulicos monocromáticos (cinza) originais, atestados por fotos dos anos 40. Isto por duas razões: porque ele era primitivamente assim e porque o abuso de desenhos em seu chão prejudicaria a leitura do contexto. Esta é, pelo menos, a opinião dos que trabalharam na restauração do centro. A este propósito, veja-se que o prefeito de São Paulo, sr. Paulo Maluf, ao reeditar a referida lei que responsabiliza o proprietário do imóvel lindeiro pela manutenção da calçada, perdeu uma oportunidade de sanar um falha. E aí se faz uma pergunta: que capacidade tem um cidadão comum de restaurar um piso artístico? O resultado: remendos que desconexam totalmente os desenhos, originando um embaralhamento que compromete a paisagem urbana. Nem o projeto da nova avenida 
Paulista, em São Paulo, foi poupado: o tratamento uniforme dado à sua calçada vem sendo desfigurado em vários trechos. Assim, é graças a iniciativas de restaurações como as iniciadas em 1991 que se desperta a consciência da função do piso no paisagismo e, portanto, no planejamento urbano. Ainda nos falta uma versão teórica, moderna e brasileira, comprometida com a historicidade, que redefina os enunciados de Camilo Sitte, para o caso da cidade brasileira. Talvez neste contexto de preocupações tenha surgido a exposição "Pisos Urbanos", no Museu da Imagem e do Som de São Paulo, organizada por Francisco Zorzete e Bia Gayotto, na qual se evidenciaram os sucessivos pisos da cidade, da terra ao paralelepípedo.

Finalmente, conviria lembrar alguns fatos do real e do imaginário referente a pisos. Há uma inequívoca conotação de grande respeito aos pés e chão por onde passa quem merece especial consideração. Talvez, o mais antigo episódio

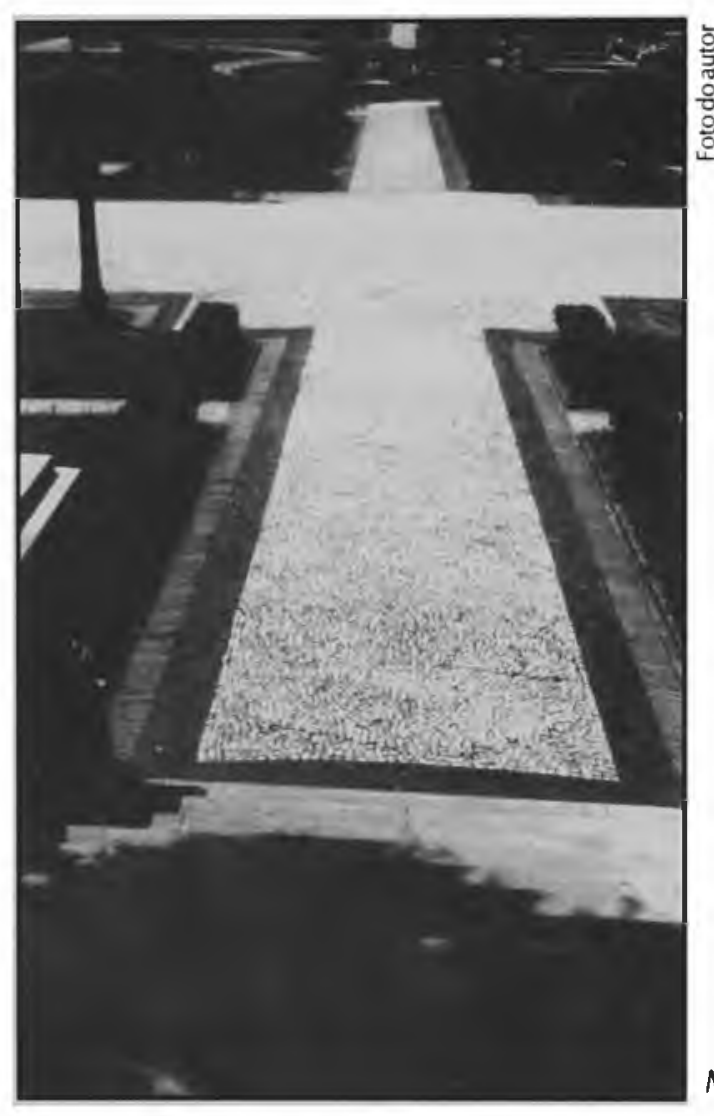
Museu do Ipiranga, SP refere-se aos ramos de arbustos que o povo de Jerusalém deita à passagem do Cristo, em sua chamada "Entrada triunfal" Mais recentemente o uso de tapetes para receber personalidades revela uma forma muito especial de deferência, assim como a célebre tradição dos estudantes de Coimbra, que iniciaram outra tradiçāo lusa. Sempre que alguém de muita importância ia visitá-los na universidade, o conjunto dos estudantes esten- 
Calçada restaurada no Monumento da Independência, SP

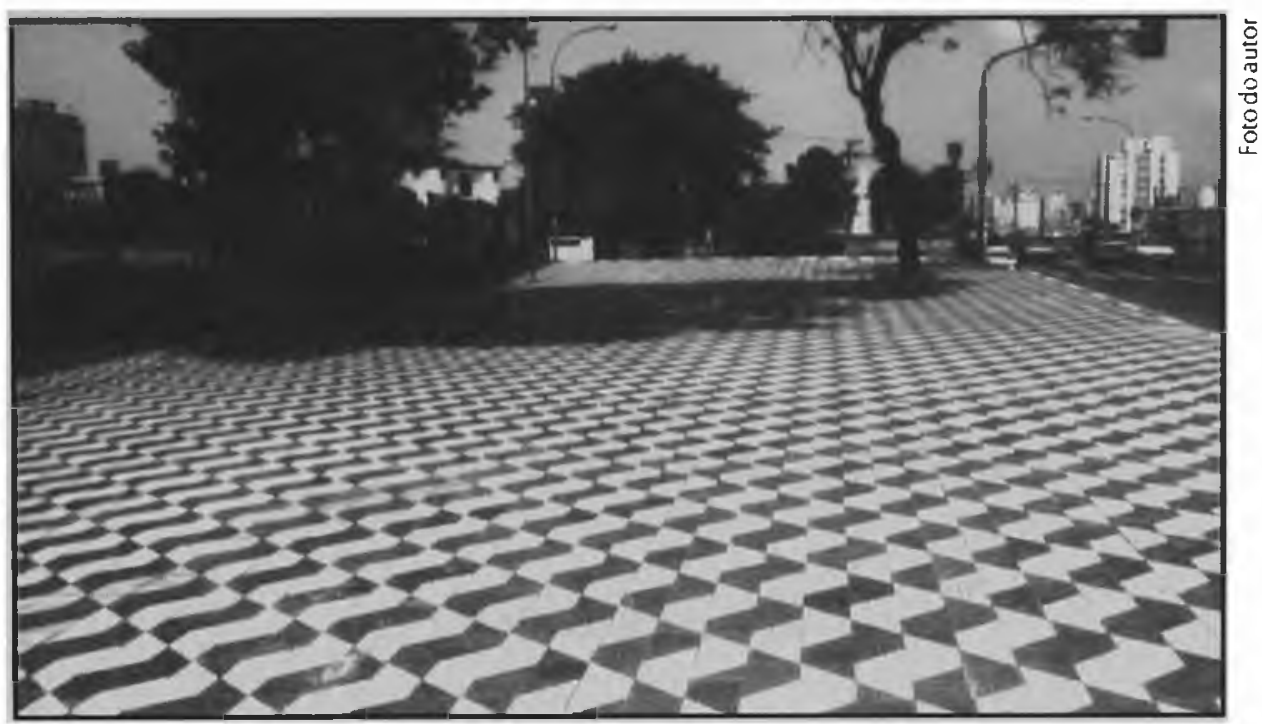

dia suas capas pretas para que o homenageado passasse. Assim também ainda são algumas procissões no Brasil e no exterior, no trajeto das quais se atapeta o caminho de passagem com flores ou desenhos feitos com serragem colorida: São Roque, $\mathrm{SP}$, é uma dessas remanescências. E entre nós, o cancioneiro popular deixa bem claro o significado de se dar um certo tratamento ao objeto amado: "Se esta rua, se esta rua fosse minha, eu mandava, eu mandava ladrilhar, com continhas, com continhas de brilhante, para o meu, para o meu amor passar..." Como ficamos então em nossa busca de construção da cidadania no que diz respeito a seus aspectos espaciais?

\section{BIBLIOGRAFIA}

ABREU, Dinis de. Passeios de Lisboa, uma arte que é de poucos e que muitos pisam sem olhar. Diário Popular, Lisboa, 10 jul. 1965.

BAIRRADA, Eduardo Martins. Empedrados artísticos de Lisboa. Lisboa: Ed. do Autor, 1986.

BRUNO, Ernani da Silva. História e tradições da cidade de São Paulo. São Paulo: Hucitec, 1984.

CASTILHO, F Pinheiro. O uso da pedra nos pavimentos, caso particular da calçada. Diário de Notícias, Lisboa, 27 out. 1965.

MARQUES, Rocha. Quando os calcetas calcetaram o Rossio. Diário de Notícias, Lisboa, 28 fev. 1944.

E além destes, os livros dos viajantes que estiveram no Brasil durante o século 19. 